\title{
PENGARUH LINGKUNGAN KERJA, PROGRAM KESELAMATAN DAN KESEHATAN KERJA TERHADAP PRODUKTIVITAS KERJA KARYAWAN PADA CV. TEHNIK PRATAMA
}

\author{
Eka Nur Safitri \\ Alumni Program Manajemen S1 \\ Sekolah Tinggi Ilmu Ekonomi Bisnis Indonesia, Jakarta \\ Syahnan S. Phalipi \\ Dosen STIE Bisnis Indonesia, Jakarta
}

\begin{abstract}
Human Resources is on of the most important factor in achieving the company goals. The limited human resources with high competency become one of the company constrain in Indonesia. Goal of this research is to know the influence of work environment, safety and occupational health to CV. Tehnik Pratama employees productivity. Methodology used is a statistical method using multiple linear regression formula with variables $\left(X_{1}\right)$ is the work environment, $\left(X_{2}\right)$ is safety, $\left(X_{3}\right)$ is occupational health and $(Y)$ is employee produktivity by distributing questionares with the number of samples equals to 52 respondens. The analisys and calculation result magnitude of correlation of which indicate is strong correlation between to variables work environment, safety, occupational health together to variable employes productivity. While the determination coefficient obtained amounted to $69.3 \%$, which means there is a significan of influence between the free variables of $69.3 \%$ and the rest variables influented $30.7 \%$.
\end{abstract}

Keywords: work environment, safety, occupational work, employee productivity

\begin{abstract}
Abstrak: Penelitian ini dilakukan untuk mengetahui bagaimana pengaruh lingkungan kerja, keselamatan dan kesehatan kerja terhadap produktivitas kerja karyawan di CV. Tehnik Pratama. Metodologi yang digunakan adalah metode statistik menggunakan rumus regresi linear berganda dengan variabel $\left(\mathrm{X}_{1}\right)$ adalah lingkungan kerja, $\left(\mathrm{X}_{2}\right)$ adalah keselamatan kerja, $\left(\mathrm{X}_{3}\right)$ adalah kesehatan kerja, dan (Y) adalah produktivitas kerja, dengan menyebarkan kuesioner kepada 52 orang karyawan yang langsung jadi responden pada CV. Tehnik Pratama. Hasil analisis dan perhitungan diperoleh besarnya koefisien korelasi (R) sebesar 0,832 yang menunjukkan bahwa adanya hubungan/korelasi yang sangat kuat antara variabel lingkungan kerja, keselamatan dan kesehatan kerja secara bersama-sama terhadap variabel produktivitas kerja karyawan. Sementara diperoleh nilai koefisien determinasi $\left(\mathrm{R}^{2}\right)$ sebesar $69,3 \%$ yang berarti terdapat pengaruh yang signifikan antara variabel bebas sebesar $69,3 \%$ terhadap variabel terikat. Sementara sisanya sebesar 30,7\% dipengaruhi oleh variabel lain.
\end{abstract}

Kata Kunci: Lingkungan Kerja, Keselamatan Kerja, Kesehatan Kerja, Produktivitas Kerja 


\section{PENDAHULUAN}

Di dalam era globalisasi saat ini perkembangan dunia usaha terasa sangat pesat. Perkembangan dunia usaha ini dapat diartikan bahwa di satu sisi memberikan peluang bisnis yang sangat besar tetapi di sisi lain memberikan tantangan dan ancaman yang patut diperhitungkan ataupun diwaspadai yaitu berupa persaingan. Oleh karena itu, perusahaan dituntut selalu siap dan mampu mengantisipasi berbagai perubahan yang terjadi di masa sekarang ataupun di masa yang akan datang. Peranan sumber daya manusia dalam suatu organisasi dinilai sangat dominan, karena bagaimanapun juga keberhasilan suatu organisasi dalam mewujudkan tujuannya akan sangat tergantung pada kemampuan sumber daya manusia yang dimilikinya. Bagi perusahaan yang berkeinginan agar dapat bekerja lebih efektif dan efisien, maka perusahaan itu tidak boleh mengabaikan pengembangan sumber daya manusianya.

Sumber daya manusia sebagai tenaga kerja tidak terlepas dari masalah-masalah yang berkaitan dengan keselamatan dan kesehatannya sewaktu bekerja. Hal ini berkaitan dengan perlindungan tenaga kerja dari bahaya dan penyakit akibat kerja maupun lingkungan kerja. Banyak hal yang dapat mempengaruhi produktivitas kerja, untuk itu perusahaan harus berusaha menjamin agar faktor yang berkaitan dengan produktivitas dapat dipenuhi secara maksimal, salah satu faktor yang mempengaruhi adalah lingkungan kerja. Kenyamanan lingkungan kerja karyawan dapat memicu karyawan untuk bekerja lebih baik sehingga produktivitas kerja dapat dicapai secara maksimal. Lingkungan kerja yang baik diharapkan dapat memacu produktivitas kerja karyawan yang tinggi. Untuk mendukung tingkat produktivitas kerja karyawan dapat dilakukan dengan menciptakan lingkungan kerja yang menyenangkan.

Lingkungan kerja merupakan segala sesuatu di sekitar pekerja dan dapat berpengaruh terhadap pekerjanya. Lingkungan kerja yang baik akan sangat besar pengaruhnya terhadap produktivitas kerja karyawan, aspek yang berpengaruh terhadap lingkungan kerja antara lain: pengaturan penerangan, tingkat kerja, kebisingan, namun penerangan disini diartikan sebagai pengaturan dan sirkulasi udara yang baik terutama di dalam lingkungan kerja, kebersihan lingkungan kerja dan keamanan terhadap barang milik karyawan.

Masalah keselamatan dan kesehatan kerja bukan semata-mata tanggung jawab pemerintah tetapi merupakan tanggung jawab semua pihak terutama pengusaha, tenaga kerja dan masyarakat. Berdasarkan PEMNAKER 05/MEN/1996, perusahaan yang mempekerjakan tenaga kerja sebanyak 100 orang atau lebih dan mempunyai potensi bahaya yang ditimbulkan oleh karakteristik proses bahan produksi yang dapat mengakibatkan kecelakaan kerja seperti peledakan, kebakaran, pencemaran dan penyakit akibat kerja, wajib menerapkan keselamatan dan kesehatan kerja. Selanjutnya Ridley (2009:118) mengemukakan definisi pelaksanaan program keselamatan dan kesehatan kerja adalah pelaksanaan program keselamatan dan kesehatan kerja merupakan salah satu bentuk upaya untuk menciptakan tempat kerja yang aman, sehat, bebas dari pencemaran lingkungan sehingga dapat mengurangi atau bebas dari kecelakaan kerja dan tidak terjadi gangguan kesehatan pada pekerja, keluarga, masyarakat dan lingkungan sekitarnya.

Program kesehatan kerja tidak terlepas dari program keselamatan kerja. Karena dua program tersebut tercakup dalam pemeliharaan terhadap karyawan. Keselamatan kerja merupakan keselamatan yang bertalian dengan mesin, alat kerja, bahan dan proses pengolahaannya, landasan tempat kerja dan lingkungan serta cara-cara melakukan pekerjaan. Sementara itu Mangkunegara (2009:161) mengemukakan bahwa istilah keselamatan mencakup istilah risiko keselamatan dan risiko kesehatan. Dalam kepegawaian kedua istilah tersebut dibedakan. Keselamatan kerja menunjukkan kondisi yang aman atau selamat dari penderitaan, kerusakan atau kerugian di tempat kerja. Risiko keselamatan merupakan aspek-aspek dari lingkungan kerja yang dapat 
menyebabkan kebakaran, tegangan arus listrik, terpotong, luka memar, patah tulang dan lain-lain. Sedangkan kesehatan kerja menunjukkan kondisi yang bebas dari gangguan fisik, mental, emosi atau rasa sakit yang disebabkan oleh lingkungan kerja.

Oleh karena itu CV. Tehnik Pratama menganggap perlindungan terhadap tenaga kerja sangat diperlukan agar perusahaan tidak kehilangan tenaga kerja yang berakibat menghambat proses produksi yang akan merugikan perusahaan akibat kecelakaan di tempat kerja tersebut. CV. Tehnik Pratama juga perlu menyediakan ruangan yang luas untuk proses produksi serta penerangan yang cukup di tempat kerja. Perusahaan yang menganggap perlindungan kerja itu penting tentunya akan memperhatikan hal-hal tersebut di atas untuk menghindari menurunnya produksi dari perusahaan, sebab dengan adanya kecelakaan kerja tersebut dapat pula mengakibatkan menurunnya produktivitas karyawan. Dari uraian di atas, maka dalam penelitian ini peneliti mengambil judul "Pengaruh Lingkungan Kerja, Program Keselamatan dan Kesehatan Kerja Terhadap Produktivitas Kerja Karyawan Pada CV. Tehnik Pratama”.

\section{TINJAUAN TEORI}

\subsection{Manajemen}

Manajemen berasal dari bahasa Inggris yaitu management yang dikembangkan dari kata to manage yang artinya mengatur atau mengelola. Kata manage berasal dari bahasa Italia, mannegio yaitu yang diadopsi dari bahasa Latin managiare, yang berasal dari kata manus, yang artinya tangan. Stone dan Freeman dalam Sunyoto (2012:3) mendefinisikan manajemen adalah proses perencanaan, pengorganisasian, pemimpinan dan pengendalian upaya organisasi dan proses penggunaan semua sumber daya organisasi untuk tercapainya tujuan organisasi yang telah ditetapkan. Terry dalam Daryanto dan Abdullah (2013:2) manajemen adalah pencapaian tujuan yang ditetapkan terlebih dahulu dengan mempergunakan kegiatan orang lain. 4 Fungsi manejemen Menurut Terry dalam Daryanto dan Abdullah (2013:2) yaitu:
a. Planning
b. Organizing
c. Actuatin
d. Controlling

\subsubsection{Kecelakaan}

Sulaksmono dalam Santoso ( 2005:15) kecelakaan adalah suatu kejadian tak diduga dan tidak dikehendaki yang mengacaukan proses suatu aktivitas yang telah diatur. Menurut Sugeng, et. al (2005:5) kecelakaan kerja adalah suatu kejadian atau peristiwa yang tidak diinginkan yang merugikan terhadap manusia, merusak harta benda atau kerugian terhadap proses. Menurut Suma'mur (2007:21) Kecelakaan akibat kerja adalah kecelakaan yang berhubungan dengan kerja pada perusahaan. Secara umum kecelakaan kerja dibagi menjadi dua golongan yaitu:

1. Kecelakaan industri (industrial accident) yaitu kecelakaan yang terjadi di tempat kerja karena adanya sumber bahaya atau bahaya kerja.

2. Kecelakaan dalam perjalanan (community accident) yaitu kecelakaan yang terjadi di luar tempat kerja yang berkaitan dengan adanya hubungan kerja.

Menurut Peterson dalam Suardi (2005:83) memodifikasi teori Domino Heinrich dengan mengemukakan teori manajemen yang berisikan lima faktor dalam urutan suatu kecelakaan yaitu: manajemen, sumber penyebab dasar, gejala, kontak dan kerugian. Birds mengemukakan bahwa 
usaha pencegahan kecelakaan kerja hanya dapat berhasil dengan mulai memperbaiki manajemen keselamatan dan kesehatan kerja.

\subsubsection{Lingkungan Kerja}

Lingkungan kerja adalah tempat di mana karyawan melakukan aktivitas setiap harinya. Lingkungan kerja yang kondusif memberikan rasa aman dan memungkinkan karyawan untuk dapat bekerja optimal. Lingkungan kerja dapat mempengaruhi emosi karyawan. Jika karyawan menyenangi lingkungan kerja di mana dia bekerja, maka karyawan tersebut akan betah di tempat kerjanya, melakukan aktivitas sehingga waktu kerja dipergunakan secara efektif. Lingkungan kerja itu mencakup hubungan kerja yang terbentuk antara sesama karyawan dan hubungan kerja antara bawahan dan atasan serta lingkungan fisik tempat karyawan bekerja. Yang dimaksud dengan lingkungan menurut Nitisemito (2005:66) adalah segala sesuatu yang tampak dan terdapat dalam alam kehidupan yang senantiasa berkembang Menurut Sedarmayanti (2007:21) jenis lingkungan kerja terbagi menjadi 2 yaitu: lingkungan kerja fisik dan lingkungan kerja nonfisik.

1. Lingkungan Kerja Fisik

Menurut Sedarmayanti (2007) lingkungan kerja fisik adalah semua yang terdapat di sekitar tempat kerja yang dapat mempengaruhi pegawai baik secara langsung maupun tidak langsung.

2. Lingkungan Kerja Nonfisik

Menurut Sedarmayanti (2007) menyatakan bahwa lingkungan kerja nonfisik adalah semua keadaan yang terjadi yang berkaitan dengan hubungan kerja, baik dengan atasan maupun dengan sesama rekan kerja ataupun hubungan dengan bawahan.

\subsubsection{Keselamatan Kerja}

Perlindungan tenaga kerja meliputi beberapa aspek dan salah satunya yaitu perlindungan keselamatan. Perlindungan tersebut bermaksud agar tenaga kerja secara aman melakukan kerjaannya sehari-hari untuk meningkatkan produksi dan produktivitas. Tenaga kerja harus memperoleh perlindungan dari berbagai sosial di sekitarnya dan pada dirinya yang dapat menimpa atau mengganggu dirinya serta pelaksanaan pekerjaannya. Menurut Ramli (2010:6) keselamatan kerja adalah kebutuhan setiap manusia untuk mengantisipasi berbagai bahaya di sekitar lingkungannya. Sedangkan menurut Sinungan (2005:356) keselamatan kerja adalah perlindungan para pekerja dari luka-luka yang diakibatkan oleh kecelakaan yang berkaitan dengan pekerjaan.

\subsubsection{Kesehatan Kerja}

Mangkunegara (2009:161) kesehatan kerja merupakan suatu hal yang penting dan perlu diperhatikan oleh pihak pengusaha. Karena dengan adanya program kesehatan yang baik akan menguntungkan para karyawan secara material, karena karyawan akan lebih jarang absen, bekerja dengan lingkungan yang lebih menyenangkan, sehingga secara keseluruhan karyawan akan mampu bekerja lebih lama. Menurut Soepomo (2007:75) kesehatan kerja adalah aturan-aturan dan usaha-usaha untuk menjaga buruh dari kejadian atau keadaan perburuhan yang merugikan kesehatan dan kesusilaan dalam seseorang itu melakukan pekerjaan dalam suatu hubungan kerja. Status sehat seseorang menurut Blum dalam Sugeng et. al (2005:9) ditentukan oleh empat faktor yaitu:

1) Lingkungan: lingkungan fisik, kimia, biologi dan sosial budaya.

2) Perilaku: sikap, kebiasaan dan tingkah laku. 
3) Pelayanan kesehatan: perawatan, pengobatan, pencegahan kecacatan.

4) Genetik yang merupakan faktor bawaan setiap manusia.

\subsubsection{Produktivitas Kerja}

Setiap perusahaan selalu berusaha agar karyawan bisa berprestasi dalam bentuk memberikan produktivitas kerja yang maksimal. Produktivitas kerja karyawan bagi suatu perusahaan sangatlah penting sebagai alat pengukur keberhasilan dalam menjalankan usaha. Karena semakin tinggi produktivitas kerja karyawan dalam perusahaan, berarti laba perusahaan dan produktivitas akan meningkat. Produktivitas kerja merupakan suatu konsep yang menunjukkan adanya kaitan output dengan input yang dibutuhkan seorang tenaga kerja untuk menghasilkan produk. Menurut Suma'mur (2007:105) produktivitas dapat diartikan sebagai perbandingan antara hasil-hasil yang dicapai dengan keseluruhan sumber daya yang dipergunakan atau perbandingan jumlah produksi (output) dengan sumber daya yang digunakan (input). Pengukuran produktivitas dilakukan dengan melihat jumlah output yang dihasilkan oleh setiap karyawan selama sebulan. Seorang karyawan dapat dikatakan produktif apabila ia mampu menghasilkan jumlah produk yang lebih banyak dibandingkan dengan karyawan lain dalam waktu yang sama.

Menurut Suma'mur (2007:109) produktivitas kerja merupakan suatu sikap mental yang selalu mempunyai pandangan bahwa mutu kehidupan hari harus lebih baik dari kemarin dan hari esok lebih baik dari hari ini. Konsep universal yang bertujuan untuk menyediakan lebih banyak barang dan jasa untuk lebih banyak manusia, dengan menggunakan sumber-sumber riil yang makin sedikit, karena setiap kegiatan memerlukan produktivitas dalam pelaksanaannya. Faktor-faktor yang mempengaruhi produktivitas menurut Simanjuntak dalam Sutrisno (2009:103) yaitu:

1. Pelatihan

2. Mental dan kemampuan fisik karyawan

3. Hubungan antara atasan dan bawahan

\subsection{Kajian-Kajian Terdahulu}

Penilitian terdahulu diantaranya sebagai berikut:

Anggreni (2012:1-5) melakukan penelitian bahwa metode analisis data dengan regresi berganda, Uji signifikan dan determinasi menyimpulkan ada pengaruh secara bersama-sama jaminan kesehatan dan kesejahteraan kerja terhadap produktivitas kerja karyawan di bagian produksi pada CV. Agung di Klaten, $F_{\text {hitung }}>F_{\text {tabel }}$ yaitu 6,362 $>$ 4,17. Serta secara individu jaminan kesehatan dan jaminan kesejahteraan berpengaruh terhadap produktivitas kerja karyawan pada CV. Agung di Klaten, untuk variabel independent jaminan kesehatan kerja nilai $t_{\text {hitung }}>t_{\text {tabel }}$ yaitu 2,215 $>$ 2,048 dan kesejahteraan kerja nilai $\mathrm{t}_{\text {hitung }}>\mathrm{t}_{\text {tabel }}$ yaitu $2.104>2$ 2,048. Jadi variabel independent yang lebih berpengaruh terhadap produktivitas adalah jaminan kesehatan kerja.

Sulistyarini (2006:73-93) melakukan penelitian bahwa metode penelitian yang digunakan adalah validitas dan reliabilitas untuk mengukur kuesioner, regresi berganda, uji stastistik yaitu uji F dan uji t menggunakan sampel 30 respoden dengan hasil variabel program keselamatan kerja dan kesehatan kerja berpengaruh secara bersama-sama terhadap variabel dependent. Hal ini terbukti dengan hasil perhitungan SPSS yang menyatakan bahwa nilai $\mathrm{F}_{\text {hitung }} 7,485$ yaitu lebih besar dari nilai $\mathrm{F}_{\text {table }}$. Variabel program keselamatan kerja dan kesehatan kerja berpengaruh secara individual terhadap produktivitas kerja karyawan. Nilai $t_{\text {hitung }}$ untuk program keselamatan kerja $\left(X_{1}\right)$ 2,102 $>t_{\text {tabel }}$ 2,048. Nilai $t_{\text {hitung }}$ untuk program kesehatan kerja $\left(X_{2}\right) 2,494>t_{\text {tabel }}$ 2,048. Dan variabel yang dominan kesehatan kerja $\left(\mathrm{X}_{2}\right)$. 


\subsection{Kerangka Pikir}

Berdasarkan perumusan dan tujuan penelitian, maka dapat digambarkan kerangka pemikiran pengaruh lingkungan kerja, program keselamatan dan kesehatan kerja terhadap produktivitas kerja karyawan. CV. Tehnik Pratama adalah salah satu perusahaan yang telah menerapkan program keselamatan dan kesehatan kerja, hal ini menunjukkan bahwa CV. Tehnik Pratama sangat memperhatikan keselamatan dan kesehatan kerja karyawannya.

\section{Gambar 2.1}

\section{Skematik Kerangka Pikir}

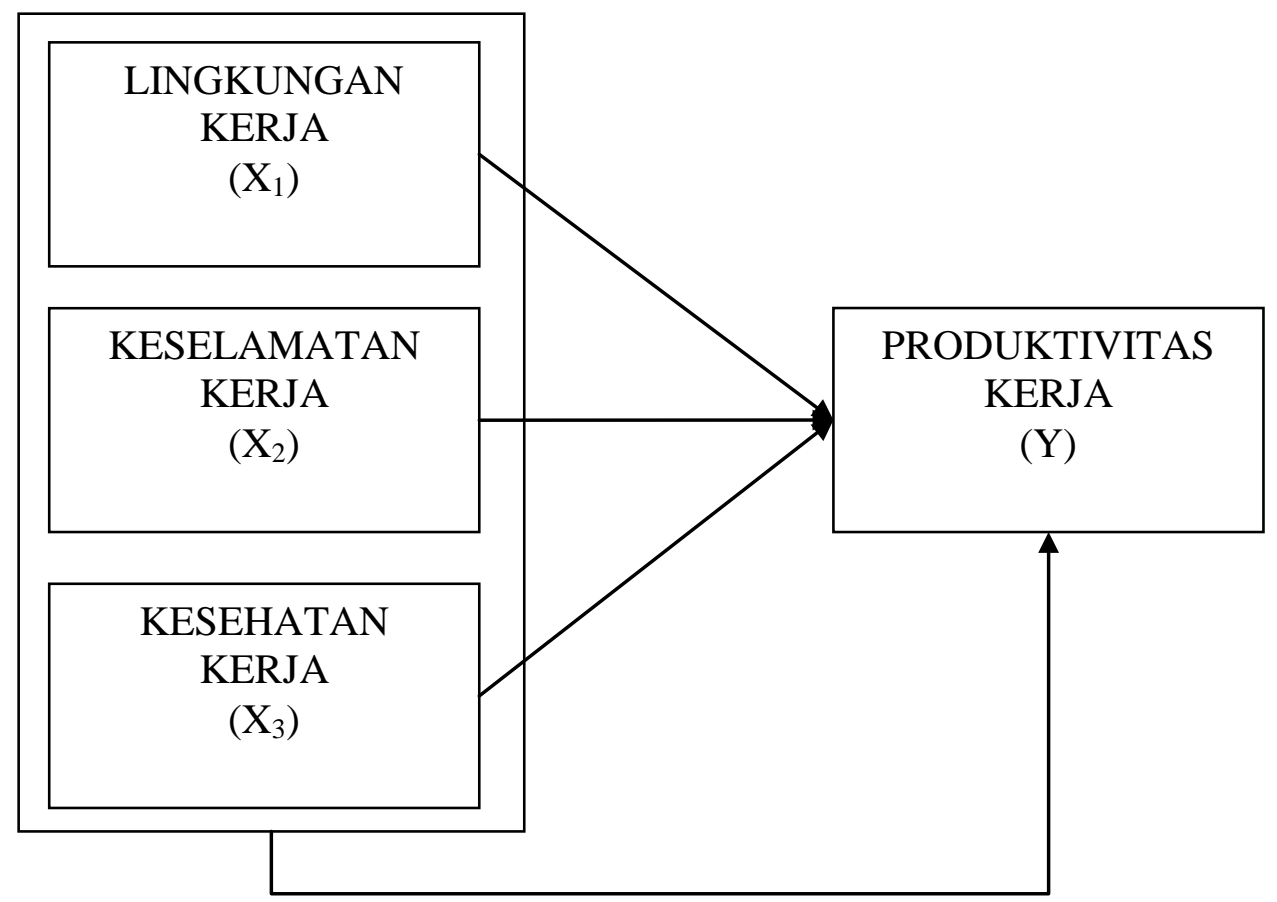

Sumber: data diolah penulis

\section{METODOLOGI PENELITIAN}

\subsection{Metode Penelitian}

Metode penelitian merupakan suatu cara penulis dalam menganalis data. Menurut Sugiyono (2009:2) metode penelitian merupakan cara ilmiah untuk mendapatkan data yang valid dengan tujuan dapat ditemukan, dibuktikan dan dikembangkan suatu pengetahuan sehingga gilirannya dapat digunakan untuk memahami, memecahkan dan mengantisipasi masalah.

\subsubsection{Tempat dan Waktu Penelitian}

Objek penelitian yang dipilih oleh penulis adalah CV. Tehnik Pratama yaitu suatu perusahaan yang bergerak di bidang jasa, machining dan fabrication, yang berlokasi di Jl. Raya PilarSukatani, Kp.Kebon Kelapa RT 002 RW 009, Karangasih, Cikarang Utara. Adapun waktu 
penelitian yang penulis lakukan adalah selama 1 bulan dimulai dari tanggal 10 Mei 2013 sampai dengan tanggal 11 Juni 2013. Penelitian ini dilakukan untuk mengetahui sejauh mana pengaruh lingkungan, program keselamatan dan kesehatan terhadap produktivitas kerja karyawan CV. Tehnik Pratama.

\subsubsection{Variabel Penelitian}

Menurut Sugiyono (2009:59) variabel penelitian pada dasarnya adalah segala sesuatu yang berbentuk apa saja yang ditetapkan oleh peneliti untuk dipelajari sehingga diperoleh informasi tentang hal tersebut, kemudian ditarik kesimpulannya. Berdasarkan hipotesis maka variablevariable dalam penelitian ini yaitu:

1. Variabel Bebas (Independent Variable)

2. Variabel Terikat (Dependent Variable)

\subsubsection{Operasional Variabel}

Agar lebih jelas untuk mengetahui variabel penelitian yang penulis gunakan dalam penelitian ini dapat dilihat pada tabel berikut ini:

Tabel 3.1

Operasional Variabel

\begin{tabular}{|c|c|c|c|}
\hline Variabel & Konsep variabel & Indikator & Skala \\
\hline $\begin{array}{c}\text { Lingkungan } \\
\text { Kerja } \\
\left(\mathrm{X}_{1}\right)\end{array}$ & $\begin{array}{l}\text { Semua yang } \\
\text { terdapat di sekitar } \\
\text { tempat kerja yang } \\
\text { dapat } \\
\text { mempengaruhi } \\
\text { pegawai baik } \\
\text { secara langsung } \\
\text { maupun tidak } \\
\text { langsung. }\end{array}$ & $\begin{array}{l}\text { Indikator-indikator lingkungan kerja } \\
\text { meliputi: } \\
\text { 1) penerangan } \\
\text { 2) suhu udara } \\
\text { 3) sirkulasi udara } \\
\text { 4) ukuran ruang kerja } \\
\text { 5) tata ruangkerja } \\
\text { 6) privasi ruang kerja } \\
\text { 7) kebersihan } \\
\text { 8) suara bising } \\
\text { 9) penggunaan warna } \\
\text { 10) peralatan kantor } \\
\text { 11) keamanan kerja } \\
\text { 12) musik ditempat kerja } \\
\text { 13) hubungan sesama rekan kerja } \\
\text { hubungan kerja antara atasan dengan } \\
\text { bawahan. }\end{array}$ & Likert \\
\hline $\begin{array}{c}\text { Keselamatan } \\
\text { Kerja } \\
\left(\mathrm{X}_{2}\right)\end{array}$ & $\begin{array}{l}\text { Rangkaian usaha } \\
\text { untuk } \\
\text { menciptakan } \\
\text { suasana kerja } \\
\text { yang aman dan }\end{array}$ & $\begin{array}{l}\text { Indikator-indikator keselamatan kerja } \\
\text { meliputi: } \\
\text { 1. Tempat Kerja } \\
\text { Lokasi dimana para karyawan } \\
\text { melaksanakan aktifitas kerjanya. }\end{array}$ & Likert \\
\hline
\end{tabular}




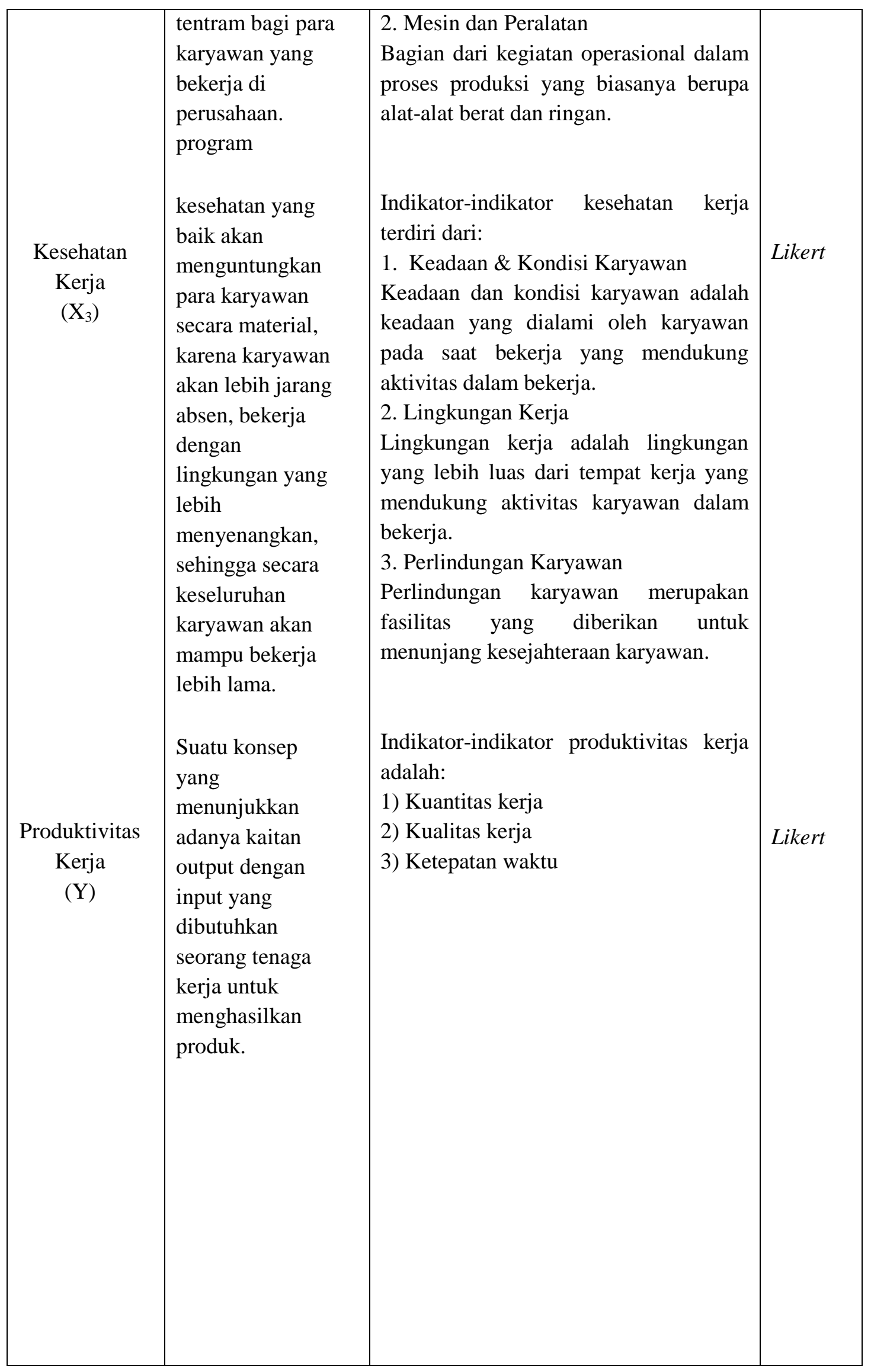




\subsection{Populasi Dan Sampel}

\section{Populasi}

Menurut Sugiyono (2009:115) populasi adalah wilayah generalisasi yang terdiri atas obyek atau subyek yang mempunyai kualitas dan karakteristik tertentu yang ditetapkan oleh peneliti untuk mempelajari dan kemudian ditarik kesimpulannya. Dalam penelitian ini yang menjadi populasi adalah seluruh karyawan CV. Tehnik Pratama yang berjumlah 109 orang.

\section{Sampel}

Menurut Sugiyono (2009:116) sampel adalah bagian dari jumlah dan karakteristik yang dimiliki oleh populasi tersebut. Menurut Sarjono dan Julianita (2011:21) sampel adalah sebagian dari populasi, terdiri dari beberapa anggota populasi. Ukuran dari sampel yang akan dijadikan objek penelitian ditentukan dengan pendekatan rumus slovin dengan persentase sampling error yang ditoleransi $10 \%$ adalah sebagai berikut:

$$
n=\frac{N}{1+N\left(e^{2}\right)}
$$

Keterangan:

$$
\begin{aligned}
& \begin{array}{l}
\mathrm{n}=\text { ukuran sampel } \\
\mathrm{N}=\text { ukuran populasi } \\
\mathrm{e}=\text { batas kesalahan }
\end{array} \\
& \mathrm{n}=\frac{109}{1+109\left(0.1^{2}\right)} \\
&=52,15(\text { dibulatkan } 52)
\end{aligned}
$$

Jadi dari anggota populasi yang diambil sebagai sampel adalah sebanyak 52 orang responden. Dalam teknik pengambilan sampel digunakan simple random sampling dengan metode simple random sampling yaitu pengambilan sampel secara acak tanpa memperhatikan strata.

\subsection{Teknik Pengolahan Dan Analisis Data}

\subsubsection{Teknik Pengolahan Data}

Sedangkan pengukuran data yang digunakan penulis yaitu skala likert, yang mengukur sikap, pendapat dan persepsi seseorang atau sekelompok orang tentang fenomena sosial. Yakni angkaangka yang dinilai berdasarkan tingkatan yaitu seperti yang diperlihatkan pada tabel 3.2 sebagai berikut:

Tabel 3.2

Skala Likert

\begin{tabular}{|l|c|}
\hline Alternatif & Bobot \\
\hline Sangat Setuju & 5 \\
\hline
\end{tabular}




\begin{tabular}{|l|l|}
\hline Setuju & 4 \\
Netral & 3 \\
Tidak setuju & 2 \\
Sangat Tidak Setuju & 1 \\
\hline
\end{tabular}

\subsubsection{Uji Validitas dan Reliabilitas}

1. Uji Validitas

Menurut Sekaran (2006:248) dalam Haryadi dan Julianita (2011:35) validitas adalah bukti bahwa instrumen, teknik atau proses yang digunakan untuk mengukur sebuah konsep yang dimaksudkan. Uji Validitas bertujuan untuk mengukur valid tidaknya suatu item pernyataan. Perhitungan validitas menggunakan SPSS dengan melihat correted item total correlation, keputusannya apabila $r_{\text {hitung }}>r_{\text {tabel }}$ maka pernyataan tersebut valid. Uji validitas ini menggunakan level signifikan $5 \%$.

2. Uji Reliabilitas

Menurut Sekaran (2006:40) dalam Haryadi dan Julianita (2011:35) menyatakan bahwa keandalan (reliability) suatu pengukuran menunjukan sejauh mana pengukuran tersebut dilakukan tanpa bias (bebas kesalahan-error free). Oleh karena itu menjamin pengukuran yang konsisten lintas waktu dan lintas beragam item dalam instrumen perlu dilakukan. Perhitungan reliabilitas menggunakan, dengan melihat reliability coefficients pada alpha, keputusannya jika $r_{\text {alpha }}>r_{\text {tabel }}$ maka instrument tersebut dinyatakan reliabel. Uji reliabilitas instrumen menggunakan pengujian dengan tingkat signifikan 5\%.

\subsubsection{Uji Asumsi Klasik}

1. Uji Normalitas

Menurut Haryadi dan Julianita (2011:53) uji normalitas bertujuan untuk mengetahui normal atau tidaknya suatu distribusi data. Pada dasarnya, uji normalitas adalah membandingkan antara data yang kita miliki dan data berdistribusi normal yang memiliki mean dan standar deviasi yang sama dengan data kita. Uji Normalitas menjadi hal penting karena salah satu syarat pengujian parametric-test (uji parametrik) adalah data harus memiliki distribusi normal.

2. Uji Heteroskedastisitas

Priyatno (2012:60) menyimpulkan uji heteroskedastisitas adalah keadaan dimana terjadinya ketidaksamaan varian dari residual pada model regresi. Model regresi yang baik mensyaratkan tidak adanya masalah heteroskedastisitas. Uji heteroskedastisitas bertujuan untuk menguji apakah model regresi terjadi ketidaksamaan varians dan residual atau pengamatan lain. Jika varians dari satu pengamatan ke pengamatan yang lain tetap maka disebut homokedasitas. Model regresi yang baik adalah yang homokedasitas atau yang tidak terjadi heteroskedastisitas.

3. Uji Multikolinearitas

Uji Multikolinearitas bertujuan untuk mengetahui apakah hubungan di antara variabel bebas memiliki masalah kolerasi/hubungan yang signifikan atau tidak. Multikolinearitas adalah kolerasi yang sangat tinggi atau sangat rendah yang terjadi pada hubungan di antara variabel independent (variabel bebas) lebih dari satu.

\subsubsection{Uji Regresi Berganda}


Sarjono dan Julianita (2011:91) mengemukakan persamaan regresi berganda mengandung makna bahwa dalam suatu persamaan regresi terdapat satu variabel dependent dan lebih dari satu variabel independent. Secara umum model regresi berganda dirumuskan sebagai berikut:

$\mathrm{Y}=\mathrm{a}+\mathrm{b}_{1} \mathrm{X}_{1}+\mathrm{b}_{2} \mathrm{X}_{2}+\mathrm{b}_{3} \mathrm{X}_{3}+\varepsilon$

Keterangan:

Y : Produktivitas Kerja

a : Konstanta

$\mathrm{X}_{1}$ : Lingkungan Kerja

$\mathrm{X}_{2}$ : Keselamatan Kerja

$\mathrm{X}_{3}$ : Kesehatan Kerja

$\varepsilon$ : Error Term

$\mathrm{b}_{1}$ : Koefisien Regresi Faktor Lingkungan Kerja

$\mathrm{b}_{2}$ : Koefisien Regresi Faktor Keselamatan Kerja

$\mathrm{b}_{3}$ : Koefisien Regresi Faktor Kesehatan Kerja

\subsubsection{Analisis Koefisien Determinasi $\left(\mathbf{R}^{2}\right)$}

Priyatno (2012:56) menyatakan analisis koefisien determinasi $\left(\mathrm{R}^{2}\right)$ untuk mengetahui seberapa besar presentase sumbangan pengaruh variabel independent secara serentak terhadap variabel dependent. Koefisien ini menunjukkan berapa besar sumbangan dari variabel-variabel bebas terhadap variabel Y apabila besarnya koefisien determinasi mendekati 0,01 atau (10\%) maka berarti variabel bebas mempunyai pengaruh yang sangat kuat terhadap variabel terikat tersebut. $\mathrm{R}^{2}$ digunakan untuk menjelaskan secara umum dari variabel-variabel bebas terhadap variabel terikat dalam persamaan regresi. Bila nilai $\mathrm{R}^{2}$ mendekati nilai 0,01 maka pengaruh variabel bebas yang digunakan dalam persamaan regresi terhadap variabel terikat adalah lemah dan apabila nilai $\mathrm{R}^{2}$ mendekati nilai 1 , maka pengaruh variabel bebas yang digunakan dalam persamaan regresi terhadap variabel terikat $\mathrm{Y}$ adalah sangat kuat.

\subsubsection{Uji Hipotesis}

\section{Uji parsial (Uji t)}

Priyatno (2012:50) mengemukakan uji untuk mengetahui pengaruh variabel independent secara parsial terhadap variabel dependent, apakah pengaruhnya signifikan atau tidak. Uji parsial ini digunakan untuk mengetahui pengaruh lingkungan kerja, program keselamatan dan kesehatan kerja dengan produktivitas kerja secara individual dan digunakan untuk menguji dominasi pengaruh variabel program kesehatan karyawan.

Langkah-langkah sebagai berikut:

a. Menentukan hipotesa nihil dan hipotesa alternatif.

Ho: $\rho=0$ Secara individu lingkungan kerja, program keselamatan dan kesehatan kerja tidak berpengaruh terhadap produktivitas kerja karyawan.

Ho: $\rho \neq 0$ Secara individu lingkungan kerja, program keselamatan dan kesehatan kerja berpengaruh terhadap produktivitas kerja karyawan.

b. Level of significance $=5 \%$

c. Kesimpulan 
Dengan membandingkan $t_{\text {hitung }}$ dengan $t_{\text {tabel }}$ dapat diketahui hubungan lingkungan kerja, program keselamatan kerja dan kesehatan kerja dengan produktivitas kerja.

\section{Uji F}

Pengujian ini dilakukan untuk mengetahui apakah semua variabel independent berpengaruh terhadap variabel dependent. Langkah-langkah sebagai berikut:

a. Menentukan Ho dan Ha

Ho: $\rho$ = 0 Secara bersama-sama lingkungan kerja, program keselamatan dan kesehatan kerja tidak berpengaruh terhadap produktivitas kerja karyawan.

Ho: $\rho \neq 0$ Secara bersama-sama lingkungan kerja, program keselamatan dan kesehatan kerja berpengaruh terhadap produktivitas kerja karyawan.

b. Level of significance $=5 \%$

c. Kesimpulan

Dengan membandingkan $\mathrm{F}_{\text {hitung }}$ dengan $\mathrm{F}_{\text {tabel }}$ dapat diketahui hubungan lingkungan kerja, program keselamatan dan kesehatan kerja dengan produktivitas kerja. Untuk pengujian antar variabel independent dan dependent yang secara bersama-sama terdapat hubungan yang positif dan signifikan, dengan menggunakan statistik uji F yaitu:

$$
F=\frac{R^{2} / k}{\left(1-R^{2}\right) /(n-k-1)}
$$

Dimana: $\quad R=$ koefisien korelasi ganda

$k$ = banyaknya variabel bebas

$n=$ ukuran sampel

Maka akan diperoleh distribusi $F$ dengan ' $\mathrm{dk}$ ' pembilang ' $k$ ' dan ' $\mathrm{dk}$ ' penyebut $(n-k-1)$ dengan ketentuan: Menurut Priyatno (2012:48) dapat diketahui bahwa kesimpulannya adalah Tolak Ho jika $F_{\text {hitung }} \geq F_{\text {tabel }}$ dan Terima Ha jika $F_{\text {hitung }} \leq F_{\text {tabel. }}$. Dimana $Y$ adalah variabel terikat, a adalah konstanta dan $\mathrm{b}$ adalah koefisien regresi pada masing-masing variabel bebas.

\section{ANALISIS DAN PEMBAHASAN}

\subsection{Analisis}

Pada penelitian kali ini, membahas tentang uji yang dilakukan seperti Uji Validitas, Uji Reliabilitas, Uji Asumsi Klasik, Analisis Regresi Berganda, Uji Koefisien Korelasi, Uji Koefisien Determinasi, dan Uji Hipotesa.

\subsection{Pembahasan}

\subsubsection{Uji Validitas}

Berdasarkan hasil pengolahan data uji validitas dapat dilihat pada dibawah ini: Variabel Lingkungan Kerja $\left(\mathrm{X}_{1}\right)$, Variabel Keselamatan Kerja $\left(\mathrm{X}_{2}\right)$, Kesehatan Kerja $\left(\mathrm{X}_{3}\right)$, dan Variabel Produktivitas Kerja $(\mathrm{Y})$ dinyatakan valid karena valid karena $\mathrm{r}_{\text {hitung }}$ lebih besar dari $\mathrm{r}_{\text {tabel }}\left(\mathrm{r}_{\text {hitung }}>\right.$ 0.2262 ), sehingga kuesioner yang digunakan dapat diikutkan pada analisis selanjutnya.

\subsubsection{Uji Reliabilitas}

Uji konsistensi internal (uji reliabilitas) dilakukan dengan menghitung koefisien (Cronbach) alpha dari masing-masing instrumen dalam satu variabel. Instrumen yang dipakai dalam variabel 
tersebut dikatakan andal (reliabel) bila memiliki koefisien Cronbach alpha lebih dari 0,60 (Nunnaly dalam Imam Ghozali, 2001).

Tabel 4.1

Hasil Uji Reliabilitas

\begin{tabular}{|l|l|l|l|}
\hline Variabel & N & Cronbach's Alpha & Keputusan \\
\hline Lingkungan Kerja & 10 & 0,922 & Reliable \\
\hline Keselamatan Kerja & 10 & 0,882 & Reliable \\
\hline Kesehatan Kerja & 10 & 0,848 & Reliable \\
\hline Produktivitas Kerja & 10 & 0,965 & Reliable \\
\hline
\end{tabular}

Sumber: hasil pengolahan data penelitian 2013, SPSS 20.0

\subsubsection{Uji Normalitas}

Uji Normalitas bertujuan untuk mengetahui normal atau tidaknya suatu distribusi data. Pada dasarnya, uji normalitas adalah membandingkan antara data yang kita miliki dan data berdistribusi normal yang memiliki mean dan standar deviasi yang sama dengan data kita. Uji Normalitas menjadi hal penting karena salah satu syarat pengujian parametric-test (uji parametrik) adalah data harus memiliki distribusi normal. Distribusi normal akan membentuk satu garis lurus diagonal. Jika distribusi data normal, maka garis yang menggambarkan data sesungguhnya akan mengikuti garis diagonalnya. Dasar pengambilan keputusan pada uji normalitas ini adalah sebagai berikut:

1. Jika Sig. atau nilai probabilitas $>0,05$, maka data berdistribusi normal.

2. Jika Sig. atau nilai probabilitas $<0,05$, maka data tidak berdistribusi normal.

Berikut adalah salah satu contoh uji normalitas:

\section{Gambar 4.1}

\section{Hasil Uji Normalitas}

Normal P-P Plot of Regression Standardized Residual

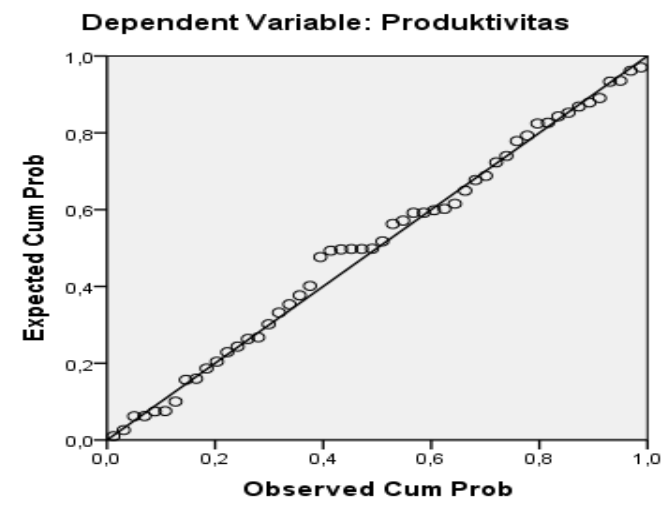

Sumber: hasil pengolahan data penelitian 2013, SPSS 20.0 
Berdasarkan grafik di atas menunjukkan bahwa semua data yang ada berdistribusi normal, karena semua data menyebar membentuk garis lurus diagonal maka data tersebut memenuhi asumsi normal atau mengikuti garis normalitas. Selain dengan melihat grafik, normalitas data juga dengan melihat uji statistik yaitu dalam penelitian ini dengan menggunakan uji statistik nonparametrik Kolmogorov-Smirnov pada alpha sebesar 5\%. Jika nilai signifikan dari pengujian Kolmogorov-Smirnov lebih besar dari 0,05 berarti data normal.

\subsubsection{Uji Multikolinearitas}

Tabel 4.2

Hasil Uji Multikolinearitas

Coefficients $^{a}$

\begin{tabular}{|c|c|c|c|c|c|c|c|c|}
\hline & \multirow[b]{2}{*}{ Model } & \multicolumn{2}{|c|}{$\begin{array}{c}\text { Unstandardized } \\
\text { Coefficients }\end{array}$} & \multirow{2}{*}{$\begin{array}{c}\text { Standardized } \\
\text { Coefficients } \\
\text { Beta }\end{array}$} & \multirow[b]{2}{*}{$\mathrm{t}$} & \multirow[b]{2}{*}{ Sig. } & \multicolumn{2}{|c|}{$\begin{array}{l}\text { Collinearity } \\
\text { Statistics }\end{array}$} \\
\hline & & B & Std. Error & & & & Tolerance & VIF \\
\hline \multirow[t]{4}{*}{1} & (Constant) & $-2,284$ & ,617 & & $-3,702$ & ,001 & & \\
\hline & Lingkungan & 145 & ,116 & 113 & 1,254 & ,216 & ,791 & 1,264 \\
\hline & Keselamatan & 648 & 153 & , 446 & 4,232 & ,000 & ,576 & 1,735 \\
\hline & Kesehatan & ,704 & 175 & ,416 & 4,034 & ,000 & ,602 & 1,662 \\
\hline
\end{tabular}

Sumber: hasil data diolah 2013, SPSS20.0

Dari data pada tabel di atas dapat diketahui bahwa syarat untuk lolos dari uji multikolinearitas sudah terpenuhi oleh seluruh variabel independent yang ada, yaitu nilai tolerance yang tidak kurang dari 0,10 dan nilai VIF (Variance Inflation Factor) yang tidak lebih dari 10 yaitu nilai VIF lebih kecil daripada $10(1,264<10)$. Maka dari itu dapat disimpulkan bahwa seluruh variabel independent yang digunakan dalam penelitian ini tidak terjadi multikolinearitas antara variabel independent satu dengan variabel independent lainnya.

\subsubsection{Uji Heteroskedastisitas}

Tabel 4.3

Hasil Uji Heterokedastisitas

\begin{tabular}{|c|c|c|c|c|c|c|}
\hline \multicolumn{7}{|c|}{ Correlations } \\
\hline & & & Lingkungan & Keselamatan & Kesehatan & $\begin{array}{l}\text { Unstandardiz } \\
\text { ed Residual }\end{array}$ \\
\hline \multirow[t]{12}{*}{ Spearman's tho } & \multirow[t]{3}{*}{ Lingkungan } & Correlation Coefficient & 1,000 & $381^{\pi x}$ & 268 &,- 072 \\
\hline & & Sig. (2-tailed) & &, 005 &, 055 & 611 \\
\hline & & N & 52 & 52 & 52 & 52 \\
\hline & \multirow[t]{3}{*}{ Keselamatan } & Correlation Coefficient &, $381^{\pi \pi}$ & 1,000 & $.461^{\pi \pi}$ &,- 056 \\
\hline & & Sig. (2-tailed) &, 005 & &, 001 &, 696 \\
\hline & & $\mathrm{N}$ & 52 & 52 & 52 & 52 \\
\hline & \multirow[t]{3}{*}{ Kesehatan } & Correlation Coefficient & 268 & $.461^{\pi \pi}$ & 1,000 & -236 \\
\hline & & Sig. (2-tailed) &, 055 & 001 & & 092 \\
\hline & & N & 52 & 52 & 52 & 52 \\
\hline & \multirow[t]{3}{*}{ Unstandardized Residual } & Correlation Coefficient &,- 072 &,- 056 & -236 & 1,000 \\
\hline & & Sig. (2-tailed) &, 611 &, 696 &, 092 & \\
\hline & & N & 52 & 52 & 52 & 52 \\
\hline
\end{tabular}

** Correlation is significant at the 0.01 level (2-tailed).

Sumber: hasil pengolahan data penelitian 2013, SPSS 20.0 
Dari hasil uji heteroskedastisitas tersebut dengan melihat unstandarized residual correlation coffetient menunjukkan bahwa nilai Sig variabel Lingkungan $\left(\mathrm{X}_{1}\right)$ adalah $>0,05$ yaitu sebesar 0,611, nilai Sig variabel Keselamatan $\left(\mathrm{X}_{2}\right)$ yaitu sebesar 0,696 dan nilai Sig Kesehatan $\left(\mathrm{X}_{3}\right)$ yaitu 0,092. Hal ini berarti Ho ketiga variabel independent tidak terjadi heteroskedastisitas.

\subsubsection{Uji Regresi Linear Berganda}

Tabel 4.3

Hasil Uji Regresi

Coefficients $^{a}$

\begin{tabular}{|c|c|c|c|c|c|c|c|c|}
\hline & \multirow[b]{2}{*}{ Model } & \multicolumn{2}{|c|}{$\begin{array}{c}\text { Unstandardized } \\
\text { Coefficients }\end{array}$} & \multirow{2}{*}{$\begin{array}{c}\begin{array}{c}\text { Standardized } \\
\text { Coefficients }\end{array} \\
\text { Beta }\end{array}$} & \multirow[b]{2}{*}{$\mathrm{t}$} & \multirow[b]{2}{*}{ Sig. } & \multicolumn{2}{|c|}{$\begin{array}{l}\text { Collinearity } \\
\text { Statistics }\end{array}$} \\
\hline & & B & Std. Error & & & & Tolerance & VIF \\
\hline \multirow[t]{4}{*}{1} & (Constant) & $-2,284$ & ,617 & & $-3,702$ & 001 & & \\
\hline & Lingkungan & ,145 & 116 & ,113 & 1,254 & ,216 & ,791 & 1,264 \\
\hline & Keselamatan & 648 & 153 & ,446 & 4,232 & ,000 & ,576 & 1,735 \\
\hline & Kesehatan & ,704 & 175 & ,416 & 4,034 & ,000 & ,602 & 1,662 \\
\hline
\end{tabular}

Sumber: hasil data diolah 2013, SPSS20.0

Apabila dari hasil output tersebut dimasukkan dalam bentuk persamaan regresi berganda adalah sebagai berikut:

$$
\begin{gathered}
Y=a+b_{1} X_{1}+b_{2} X_{2}+b_{3} X_{3}+e \\
Y=-2,284+0,145 X_{1}+0,648 X_{2}+0,704 X_{3}+e
\end{gathered}
$$

\subsubsection{Uji Koefisien Determinasi $\left(\mathbf{R}^{2}\right)$}

Tabel 4.4

Hasil Uji Koefisien Determinasi

Model Summary ${ }^{b}$

\begin{tabular}{|l|r|r|r|r|r|}
\hline Model & $\mathrm{R}$ & R Square & \multicolumn{1}{c|}{$\begin{array}{c}\text { Adjusted } R \\
\text { Square }\end{array}$} & $\begin{array}{c}\text { Std. Error of the } \\
\text { Estimate }\end{array}$ & Durbin-Watson \\
\hline 1 &, $832^{\mathrm{a}}$ &, 693 &, 674 &, 452 & 1,841 \\
\hline
\end{tabular}

Sumber: hasil pengolahan data penelitian 2013, SPSS 20.0

Adjusted $R$ Square adalah $R$ Square yang telah disesuaikan, nilai sebesar 0,674. Nilai ini menunjukkan sumbangan pengaruh variabel independent terhadap variabel dependent. Adjusted $R$ Square digunakan untuk mengukur sumbangan pengaruh jika dalam regresi menggunakan lebih dari dua variabel independent. Standard Error nof the Estimate adalah ukuran dimana kesalahan 
prediksi, nilai sebesar 0,452. Artinya kesalahan yang dapat terjadi dalam memprediksi produktivitas sebesar 0,452 .

\subsubsection{Uji Hipotesis}

1. Uji t

Tabel 4.5

Hasil Uji t

\begin{tabular}{|c|c|c|c|c|c|c|}
\hline & & \multicolumn{5}{|c|}{ Coefficients $^{a}$} \\
\hline \multirow{2}{*}{\multicolumn{2}{|c|}{ Model }} & \multicolumn{2}{|c|}{ Unstandardized Coefficients } & \multirow{2}{*}{$\begin{array}{c}\text { Standardized } \\
\text { Coefficients } \\
\text { Beta }\end{array}$} & \multirow[b]{2}{*}{$t$} & \multirow[b]{2}{*}{ Sig. } \\
\hline & & $B$ & Std. Error & & & \\
\hline \multirow[t]{4}{*}{1} & (Constant) & $-2,284$ & .617 & & $-3,702$ & 001 \\
\hline & Lingkungan & .145 &, 116 &, 113 & 1,254 &, 216 \\
\hline & Keselamatan & .648 &, 153 &, 446 & 4,232 &, 000 \\
\hline & Kesehatan & 704 & 175 & 416 & 4,034 & 000 \\
\hline
\end{tabular}

a. Dependent Variable: Produktivitas

Sumber: hasil pengolahan data penelitian 2013, SPSS 20.0

\section{Uji F}

Uji F atau uji koefisien regresi secara bersama-sama digunakan untuk mengetahui apakah secara bersama-sama variabel independent berpengaruh signifikan terhadap variabel dependent. Uji $\mathrm{F}$ akan diputuskan menerima atau menolak hipotesa yang akan menolak hipotesa yang akan diajukan.

Kriteria pengujian:

Jika $\mathrm{F}_{\text {hitung }} \leq \mathrm{F}_{\text {tabel }}$ maka Ho diterima

Jika $\mathrm{F}_{\text {hitung }} \geq \mathrm{F}_{\text {tabel }}$ maka Ho ditolak

Tabel 4.6

Hasil Uji F

ANOVA $^{b}$

\begin{tabular}{|ll|r|r|r|r|r|}
\hline Model & Sum of Squares & Df & Mean Square & F & Sig. \\
\hline 1 & Regression & 22,156 & 3 & 7,385 & 36,091 &, $000^{\mathrm{a}}$ \\
& Residual & 9,822 & 48 &, 205 & & \\
& Total & 31,978 & 51 & & & \\
\hline
\end{tabular}

a. Predictors: (Constant), Kesehatan, Lingkungan, Keselamatan

b. Dependent Variable: Produktivitas

Sumber: hasil pengolahan data penelitian 2013, SPSS 20.0 


\section{SIMPULAN DAN SARAN}

\section{1. simpulan}

Berdasarkan penelitian yang telah dilakukan oleh penulis pada CV. Tehnik Pratama, maka dapat mengambil kesimpulan sebagai berikut:

1. Hasil pengolahan data berdasarkan perbandingan pendekatan SPSS menunjukkan bahwa variabel lingkungan kerja $\left(\mathrm{X}_{1}\right)$ tidak berpengaruh signifikan terhadap variabel produktivitas kerja karyawan (Y).

2. Hasil pengolahan data berdasarkan perbandingan pendekatan SPSS menunjukkan bahwa variabel keselamatan kerja $\left(\mathrm{X}_{2}\right)$ berpengaruh secara signifikan terhadap variabel produktivitas kerja karyawan (Y).

3. Hasil pengolahan data berdasarkan perbandingan pendekatan SPSS menunjukkan bahwa variabel kesehatan kerja $\left(\mathrm{X}_{3}\right)$ berpengaruh secara signifikan terhadap variabel produktivitas kerja karyawan (Y).

4. Hasil pengolahan data berdasarkan perbandingan pendekatan SPSS menunjukkan bahwa variabel lingkungan kerja $\left(\mathrm{X}_{1}\right)$, keselamatan kerja $\left(\mathrm{X}_{2}\right)$ dan kesehatan kerja $\left(\mathrm{X}_{3}\right)$ secara bersama-sama berpengaruh signifikan terhadap variabel produktivitas kerja karyawan (Y).

\subsection{Saran}

Berdasarkan kesimpulan tersebut di atas, maka penulis dapat memberikan beberapa saran yang diharapkan dapat menjadi bahan masukan positif dan dasar pengambilan keputusan dalam usaha meningkatkan produktivitas kerja karyawan pada CV. Tehnik Pratama. Adapun saran-saran yang penulis ajukan adalah sebagai berikut:

1. Bahwa sangat penting bagi CV. Tehnik Pratama untuk melakukan penilaian lingkungan kerja sebaik dan seobjektif mungkin, karena pada dasarnya setiap karyawan ingin lingkungan kerja yang bersih, rapi mampu mendukung terciptanya produktivitas kerja karyawan.

2. Bagi pihak perusahaan untuk disarankan bagi perusahaan untuk mewajibkan dan mensosialisasikan penggunaan alat pelindung dan alat kerja, dengan jalan antara lain meningkatkan dan menerapkan Keselamatan dan Kesehatan Kerja (K3) dengan baik dan tepat. Program Keselamatan dan Kesehatan Kerja (K3) bagi karyawan, seperti misalnya dengan pemberitahuan bagaimana cara penggunaan peralatan, pemakaian alat pelindung diri, cara mengoperasionalkan mesin secara baik dan benar. Selain itu perusahaan harus meningkatkan program Keselamatan dan Kesehatan Kerja (K3) serta menerangkan prinsipprinsip Keselamatan dan Kesehatan Kerja (K3) dalam kegiatan operasional.

3. Perusahan disarankan untuk lebih memperhatikan sistem pengawasan pekerjaan karyawan, perusahaan juga harus lebih mengutamakan peraturan-peraturan kerja bagi karyawan dalam melaksanakan pekerjaan, agar tidak terjadi kecelakan yang tidak diinginkan dalam bekerja sehingga dapat meningkatkan semangat karyawan pada CV. Tehnik Pratama.

4. Perusahaan seharusnya meningkatkan kreatifitas yang dimiliki karyawan seperti mendengarkan dan menampung saran jika karyawan menyampaikan gagasan kepada pimpinan sehingga karyawan dapat menyelaikan tugas dengan batas waktu yang diberikan perusahaan.

5. Berdasarkan hasil analisa sudah seharusnya CV. Tehnik Pratama memperhatikan kuantitas kerja, kualias kerja dan ketepatan waktu untuk mengukur dan meningkatkan produktivitas kerja karyawan. 


\section{DAFTAR PUSTAKA}

Anggreni, Putri. 2012. Pengaruh K3 Terhadap Produktivitas Kerja PT. Brem Bali. Jurnal Manajemen. (Vol.21 No.1) Hal 1-5.

Handoko, Hani T. 2011. Manajemen Pemasaran Analisis Perilaku Konsumen. Yogyakarta: BPFE.

Hasibuan, Malayu S.P. 2007. Manajemen Sumber Daya Manusia, Edisi Revisi. Bumi: Aksara. Jakarta.

Husen, Abrar. 2011. Manajemen Proyek, Edisi II. Andi. Yogyakarta.

Mahardika. 2005. Pengaruh K3 Terhadap Karyawan. Jurnal Ekonomi dan Manajemen. (Vol.1 No.1) Hal. 73-78.

Mangkunegara, Anwar Prabu. 2009. Manajemen Sumber Daya Manusia Perusahaan. PT Remaja. Bandung.

Nitisemito, Alex. 2005. Wawasan Studi Kelanyakan Dan Evaluasi Proyek. Bumi Aksara. Jakarta.

Priyatno, Duwi. 2012. SPSS untuk Analisis Korelasi, Regresi, dan Multivariate. Gava Media. Yogyakarta.

Ramli S. 2010. Manajemen Keselamatan dan Kesehatan Kerja, Cetakan Kedua. Dian Rakyat. Jakarta.

Ridley, John. 2009. Ikhtisar Keselaman dan Kesehatan Kerja. Erlangga. Jakarta.

Santoso, G. 2005. Manajemen Keselamatan dan Kesehatan Kerja. Prestasi Pustaka. Jakarta.

Sarjono, Haryadi \& Julianita, Winda. 2011. SPSS VS LISREL Sebuah Pengantar Aplikasi Untuk Riset. Salemba Empat. Jakarta.

Sedarmayanti. 2007. Manajemen Sumber Daya Manusia. PT. Refika Aditama. Bandung.

Sinungan, Muchdarsyah. 2005. Produktivitas Apa dan Bagaimana. Bumi Aksara. Jakarta.

Soepomo, Iman. 2007. Hukum Perburuhan Bidang Kesehatan Kerja. PT. Pradya Paramita. Jakarta.

Sugeng, A.M. dkk. 2005. Bunga Rampai HIPERKES \&KK Edisi Kedua. Undip. Semarang.

Sugiyono. 2009. Metode Penelitian Kualitatif dan Kuantitatif. Alfabeta. Bandung.

Sule, Ernie Trisnawati. 2006. Pengantar Manajemen Jilid 2. Prenada Media. Jakarta.

Sulistyarini, Wahyu. 2006. Pengaruh Program K3 Terhadap Produktivitas Kerja CV. Sahabat Klaten. Jurnal Manajemen. (Vol.1 No.1) Hal. 73-79.

Suma’mur. 2007. Keselamatan Kerja dan Pencegahan Kecelakaan. CV. Haji Masagung. Jakarta. 